\title{
New trends in collocability based on the English collocations in fiction
}

\section{A. O. Chernousova ${ }^{1}$}

${ }^{1}$ Moscow City University, 4 Vtoroy Selskohoziajstvenny proezd, Moscow 129226, Russian Federation

DOI: 10.18255/2412-6519-2020-1-100-106

Research Article Full text in Russian

The language of fiction is probably not the most dynamically but still changing. These new trends in collacability are of a great interest to us. The definition of collocation is present in the text; the authors also distinguish the concepts of collocation and lexical function. This article will discuss the trends considered in synchrony and diachrony, which were highlighted on the material of John Grisham "Gray Mountain", which is relatively new English-language material (2014), and a bit dated J. D. Salinger "Nine Stories" (1953) to track trends and their development in the language. 150 examples were reviewed and analyzed. 5 trends were highlighted on a given case. The authors use dictionaries, linguistic search on the Internet, the COCA (Grisham and Salinger are both from the USA). The authors conclude that the trends that have been considered are the most frequent for the language of fiction and deserve the attention of the researchers due to their productivity. The reasons why stable word combinations change: the emergence of new realities and the need for a new nomination and (which is more typical for the prose) the search for the new forms of self-expression of the writers.

Keywords: collocation; lexical function; collocability; trends; neologisms

\section{INFORMATION ABOUT THE AUTHORS}

$$
\begin{array}{l|l}
\text { Chernousova A. O. } & \begin{array}{l}
\text { E-mail: ann.chernousova@yahoo.com } \\
\text { Postgraduate student }
\end{array}
\end{array}
$$

For citation: Chernousova A. O. New trends in collocability based on the English collocations in fiction // Social'nye i gumanitarnye znanija. 2020. Vol. 6, No 1. P. 100-106. (in Russ.) 


\title{
Тенденции сочетаемости на примере коллокаций в англоязычной художественной прозе
}

\author{
А. 0. Черноусова ${ }^{1}$
}

${ }^{1}$ Московский городской педагогический университет, 2-й Сельскохозяйственный проезд, 4, Москва, 129226, Российская Федерация

DOI: 10.18255/2412-6519-2020-1-100-106

УдК 811.111

Научная статья

Полный текст на русском языке

Язык художественной прозы, возможно, не самый быстро развивающийся, однако все же претерпевает изменения. Наибольший интерес для нас представляют изменения устойчивых сочетаний по типу коллокаций. Определение коллокации представлено в тексте статьи, также автор разграничивает понятия коллокации и лексической функции (термин шире, чем коллокация). В данной статье речь пойдет о тенденциях сочетаемости на примере коллокаций, рассматриваемых как в синхронии, так и в диахронии, которые были выделены и на относительно новом материале Джона Гришэма «Серая гора» (2014 г.), и на материале со сроком давности более 50 лет - Дж. Сэлинджера «Девять рассказов» (1953 г.). Цель исследования - обозначить тенденции и показать их развитие в языке. Было рассмотрено и проанализировано 150 примеров. Корпус примеров был составлен методом сплошной выборки. Были определены пять тенденций. В работе используются следующие инструменты: онлайн-словари, лингвистическая справка с помощью поисковика в глобальной сети Интернет, Корпус Современного Американского Английского Языка (т. к. оба писателя из США). Причины, по которым устойчивые сочетания изменяются: возникновение новых реалий, потребность в новой номинации и (что характерно для художественной прозы) поиск новых форм самовыражения для автора.

Ключевые слова: коллокация; лексическая функция; сочетаемость; тенденции; неологизм

ИНФОРМАЦИЯ ОБ АВТОРАХ

\begin{tabular}{l|l} 
Черноусова Анна Олеговна & $\begin{array}{l}\text { E-mail: ann.chernousova@yahoo.com } \\
\text { Аспирант }\end{array}$
\end{tabular}

Для цитирования: Черноусова А. О. Тенденции сочетаемости на примере коллокаций в англоязычной художественной прозе // Социальные и гуманитарные знания. 2020. Том 6, № 1. С. 100-106.

(C) Черноусова А. О., 2020

Статья открытого доступа под лицензией CC BY-NC-ND (http://creativecommons.org/licenses/by-nc-nd/4.0/) 
Развитие и изменение языка художественной прозы происходит как по причине общеязыковых изменений, которые возникают ввиду появления новых реалий и необходимости новой номинации, так и по причине индивидуально-авторских интенций и создания новых средств языка для выражения тонкостей эмоций и чувств.

Стоит отметить, что не всегда индивидуально-авторские коллокации являются коммуникативно значимыми для всех остальных говорящих, для этого мы ставим задачу проследить, как новые коллокации вошли в язык. Под коллокацией мы понимаем неидиоматическое словосочетание, в котором свободный компонент не меняет своего смысла, а смысл несвободного отличается от того, который реализуется в свободных словосочетаниях, он выбирается в зависимости от смысла и от основного компонента [1, с. 15]. У этого термина существует так называемое определение с помощью статистического подхода в значении комбинации слов с высокой вероятностью совместной встречаемости, и в корпусе она отражается объективными данными частотности [2, с. 135].

Мы используем корпус для проверки наличия или отсутствия в нем той или иной коллокации либо для поиска синонимичных устойчивых коллокаций по основному компоненту, однако понимаем, что чаще те коллокации, которые нас интересуют, не представлены широко в универсальном корпусе. Следует также отметить, что тексты художественной литературы статистически наименее насыщены коллокациями в отличие, например, от официально-деловых текстов и газет.

Мы также используем термин лексическая функция, введенный И. А. Мельчуком [3, с. 682], как значение сочетаемости двух лексем. В данном исследовании нас интересует ЛФ в несвободных словосочетаниях (коллокациях) [4, с. 20]. В примерах, которые мы исследовали, встретились две функции: Magn в значении «очень» и AntiMagn «слегка, менее».

Методом сплошной выборки было отобрано 150 примеров нетривиальной сочетаемости, которые впоследствии были сгруппированы по схожести признаков. Каждое сочетание анализировалось по словарю, частотность употребления [2, с. 136] и сочетаемость проверялись в поисковике глобальной сети Интернет, а также по корпусу современного американского английского языка (COCA). Данный корпус состоит из 560 млн слов и собирался из материалов с 1990 по 2017 гг. Таким образом, мы можем считать его действительно актуальным для современного языка и по нему можем проверять коллокации, отобранные из текстов произведений, написанных 60-70 лет назад. Мы отдаем себе отчет в том, что корпус и результаты, полученные опытным путем через корпус, не могут служить единственным объективным доказательством употребления в языке того или иного слова или выражения, так как не все слова и тексты включаются в корпус ввиду сбалансированности и ограниченного объема. Для этого мы применяем интернет в качестве корпуса большего размера. Материал, на базе которого отбирались коллокации, - это John Grisham «Gray Mountain», J. D. Salinger «Nine Stories». Мы используем произведения разных авторов со значительной разницей во времени выхода их произведений для того, чтобы не только найти новые коллокации и обозначить тенденции сочетаемости, но и просмотреть в диахронии путь авторских коллокаций более ранних произведений.

В данном исследовании мы ставим следующие задачи:

1) выделить тенденции в сочетаемости внутри коллокаций;

2) провести градацию популярности той или иной тенденции;

3) объяснить возникновение той или иной тенденции сочетаемости в коллокациях. 
1. Тенденция, которую мы наблюдаем, - это развитие уже сложившихся коллокаций, которые распространяются за счет новой глагольной части: the rumour had gone out of gas. Идиома run out of gas [1. to no longer have any gas in one's vehicle; 2. sometimes used figuratively to indicate getting tired] в значениях «заканчиваться» и «уставать» используется с новым глаголом go.

Рассмотрим на примере:

"Day ten passed without bloodshed, as did the next. On day twelve there was a flash of optimism as Ben, one of Samantha's colleagues, shared a rumor that credit markets in London were loosening a bit. Borrowers might find some cash after all. But late that afternoon the rumor had run out of gas; nothing to it. And so they waited».

Сначала у героев зажглась «искра оптимизма/надежды», когда прошел слух о возможном займе и сохранении рабочих мест, но позже слух не подтвердился, «иссяк», «испарился», и периферийное значение «устать» тоже реализуется, так как людям уже ничего не оставалось, как «сидеть и ждать».

В корпусе в данном составе коллокация не встречается, в то время как идиома run out of gas имеет частотность 156.

Рассмотрим другой пример work three jobs: «Jeff went to stay with another aunt and Donovan lived with us until he finished high school. He worked three jobs getting through college. By the time he graduated he knew exactly what he wanted to do: become a lawyer and spend the rest of his life fighting coal companies». (J. Grisham)

Обычное сочетание с job в данном значении будет с глаголами do, have, take, либо work уточнялось бы in three different places, в данном случае представлена не имитация речи малограмотного героя, а авторское повествование, значит, автор считает такое употребление возможным и не находит его семантически избыточным. Удивительно, что в корпусе коллокация work jobs имеет частотность 19, из которых 5 - это глагол + существительное, остальные - прилагательное + существительное, таким образом, редкая и нестандартная, выходящая за рамки нормы, семантически избыточная коллокация встречается в языке, несмотря на то, что в словарях не зафиксирована.

2. Следующая тенденция, которую мы наблюдаем, - это расширение сложившейся коллокации за счет новой именной части.

Выражение to recap [to repeat the main points of an explanation or description] the mess [a situation that is full of problems]

(«The three associates studied their feet, waiting. Samantha felt the urge to grab Ben's hand, like a terrified prisoner facing a firing squad. Andy fell into his chair, and, avoiding eye contact but desperate to get things over with, he recapped the mess they were in» (J. Grisham)) в значении «коротко и по сути изложить ту неприятную ситуацию, в которой оказалась компания», находится на начальной стадии, свободное сочетание меняется за счет введения существительного с новой семантикой.

Наиболее частотная сочетаемость глагола recap - с предлогом on, чаще всего без имени существительного. В корпусе современного американского английского языка COCА наиболее частотные варианты: recap the season, recap on what we decided.

3. Еще одна тенденция, которую мы выделили, - это расширение именной части коллокаций за счет существительных, обозначающих новые реалии. Рассмотрим пример: do the pink slip thing. Глагол do позволяет ввести коллокацию, где именная часть pink slip [a document given to a person saying that they do not have a job any more] обозначает карточку, которую выдает отдел кадров при увольнении 
в США. С помощью метонимического переноса это словосочетание вошло в употребление в значении «прекращение работы/увольнение». Термин pink slip не является новым, Оксфордский словарь фиксирует первое употребление в 1915 году, однако коллокация с do является низкочастотной, но построенной с помощью продуктивной модели и потому понятной носителям языка.

Подобный пример мы встречаем в употреблении выражения study smb's cell phone: «On the thirty-ninth floor, the elevator stopped again, and Mr. Kirk Knight got on board while studying his cell phone» (J. Grisham). Study обычно используется в значении «to examine something very carefully». С неологизмом cell phone образовалась новая сочетаемость, которая описывает новую реальность в отличие от, например, выражения study the report, где глагол подчеркивает умственную деятельность и внимательное изучение чего-либо вообще, чего нет в значении выражения study the cell phone: глагол имеет отношение к свободному, а сочетание несвободное. В корпусе данное выражение также не зафиксировано.

Рассмотрим также пример a made-for-tourists rip-off [an act of cheating someone by charging too much or not giving anything of value for money spent], где наблюдается несвободная сочетаемость с существительным rip-off, которая развилась за счет необходимости спецификации значения, и новые реалии - туризм, который бурно развивается последние годы, а также мелкое мошенничество как неотъемлемая часть любой сферы человеческой жизнедеятельности.

4. Тенденция, которая прослеживается в адъективных коллокациях, конструкции наречие + прилагательное + существительное, - усиление прилагательного за счет нетипичного наречия в значении лексической функции Magn [5].

Представленные наречия, являются очень типичными для функции Magn: terribly, extremely, wonderfully. Однако рассмотрим подробнее каждый пример:

- wonderfully unburdened [not burdened: having no weight or load]: «The relief came from the sudden realization that she had just been freed from a job she despised. Tonight at seven she might be watching a movie or having dinner with friends, not slaving away at the office with the meter running. This Sunday she could leave the city with no thoughts whatsoever about Andy Grubman and the pile of paperwork for his next crucial deal. The FirmFone, a monstrous little gadget that had been glued to her body for three years now, had been surrendered. She felt liberated and wonderfully unburdened» (J.Grisham). Интересен тот факт, что в корпусе СОСА этот вариант употребления и именно этот фрагмент зафиксирован с частотностью 1.

- terribly penetrating [used to describe a way of looking at someone in which you seem to know what they are thinking] eyes: "Not that one's appearance matters greatly, but he was. He had terribly penetrating eyes, for a man who was intrinsically kind» (J. D. Salinger) Данная коллокация встречается в корпусе COCА с частотностью 1, но не из этого же источника, что говорит о том, что в язык она вошла, но не стала частотной.

- hopelessly sincere handwriting: «Written in ink, in German, in a small, hopelessly sincere handwriting, were the words "Dear God, life is hell"» (J. D. Salinger). Автор прибегает к метафоре, использует непопулярную и нечастотную коллокацию либо делает попытку авторского неологизма, выражая «искренность, которая демонстрирует отчаяние». Американский офицер, квартированный в доме семьи, которая имела отношение к Нацистской партии, находит книгу Геббельса, в которой уже арестованная им же 38-летняя девушка, член низшего ранга Нацистской партии, на пустой странице книги пишет на немецком обращение к Богу: «жизнь - ад». Дж. Сэлинджер, сам будучи американским офицером и прошедшим войну от дня высадки в Европу до дня 
победы, а также будучи евреем по отцу, женившимся на немке, имеющей принадлежность к Нацистской партии, вероятно, показывал некоторое отношение через описание почерка человека, его собственное противоречивое отношение к ситуации выражено и в самом сочетании. Hopelessly sincere, к слову, не представлено в корпусе, однако поисковик Google выдает достаточное количество книг, где авторы используют коллокацию. Книги, которые выдает поисковик: письма MacNeice (1932), книга религиозной тематики (2010), художественная проза 2009, 2016 гг., что говорит о том, что данное выражение прошло довольно длинный временной путь и закрепилось в языке, пусть и не в повседневной речи, а всего лишь в книжной лексике.

- extremely squalid and moving: «Make it extremely squalid [very dirty and unpleasant] and moving [causing strong feelings of sadness or sympathy]» she suggested. «Are you at all acquainted with squalor?» (J. D. Salinger) Extremely moving встречается в корпусе с частотностью 16, а вот extremely squalid не встречается вовсе, в этом и проявляется лингвокреативность автора: усилительное наречие, используемое одновременно для однородных прилагательных, которые при этом находятся по смыслу в антонимических отношениях, показывает необычность говорящего, его неординарность в некотором роде. Автор намеренно прибегнул к нарушению сочетаемости с целью привлечения внимания к герою через его речь.

- extremely gifted [clever, or having a special ability] genius [very great and rare natural ability or skill, especially in a particular area such as science or art, or a person who has this]: «My mother was quite a passionate woman. She was an extrovert. Father was an introvert. They were quite well mated, though, in a superficial way. To be quite candid, Father really needed more of an intellectual companion than Mother was. He was an extremely gifted genius» (J. D. Salinger). Extremely gifted имеет частотность 25 в корпусе, однако gifted genius не встречается ни в корпусе, ни в поисковике, оно и объяснимо, так как сочетание является семантически избыточным, и дополнение наречием возводит признак в самую высокую степень, что характерно для речи ребенка, особенно, когда он желает приукрасить что-либо.

- the deadliest Russian gangsters ("In the other corner was Krull Mining, a company with the worst safety record in the history of U.S. coal production and an owner who was reputed to be one of the deadliest Russian gangsters in Putin's frat pack» (J. Grisham)) в таком виде не встречается в Корпусе по ряду причин: 1) gangster как реалия прошлого теряет частотность, 2) deadliest употребляется чаще со следующими существительными: accident/disaster/animal/attack/form of disease, с людьми, как правило, не используется, это делает сочетание наиболее семантически емким, показывает отношение к предмету разговора.

- the required pleasantries: "They sat in the den and went through the required pleasantries» [a short polite conversation before the serious conversation] (J. Grisham). Данное сочетание не встречается в корпусе, pleasantries в значении «формальные шутки для установки диалога» некоторым образом усиливается словом required, добавляя значение формальности/стандартности/ происходящего.

5. Anti Magn

Рассмотрим сочетание trifle posture-conscious: «"Really," she said, "I wasn't quite bom yesterday, you know." I said I'd bet she hadn't been, at that. I drank my tea for a moment. I was getting a trifle posture-conscious and I sat up somewhat straighter in my seat» (J. D. Salinger). A trifle используется в значении slightly, в то время как posture-conscious - окказиональное слово, образованное по живой модели (a bargain-conscious shopper, a budget-conscious businessman, a race-conscious society). Окказиональное слово posture- 
conscious нужно было ввести, сочетаемость с ним по определению является устойчивой. Как показывают поисковик и корпус, сочетание не задержалось в языке, однако в произведении Дж. Сэлинджера оно существует в таком виде и вместе несет функцию Anti Magn.

Результаты, к которым мы пришли:

1. В равной степени представлены «новые» коллокации, которые образовались как за счет новой именной части, так и за счет глагольной (глагол, близкий по смыслу, уточняющий для данного контекста, однако новый для уже существующего устойчивого сочетания).

2. Большую долю в примерах образовали коллокации, которые расширились за счет существительных и представляют новые реалии. Это естественный процесс жизни и языкотворчества, новые предметы и явления создают привычное языковое окружение и образуют новые коллокации.

3. Адъективные коллокации по типу наречие + прилагательное или наречие=прилагательное + существительное в художественной прозе представлены широко, чаще всего автору требуются новые средства для уточнения, описания, привлечения внимания, и создаются новые коллокации со значением лексических функций Magn и Anti Magn.

Судя по нестандартным коллокациям, которые анализировались на материале Дж. Сэлинджера, мы можем сказать, что далеко не все индивидуально-авторские коллокации задерживаются в языке и становятся употребляемыми другими носителями.

\section{Ссылки / References}

1. Кицей Е. Н. Сопоставительное исследование средств выражения значения действия с помощью устойчивых глагольно-именных словосочетаний: дис. ... канд. филол. наук: 10.02.20. М., 2008. 230 c.

2. Черноусова А. О. Исследование письменного перевода коллокации с русского языка на английский с применением корпусов английского языка // Филология и культура. Philology and culture. 2018. № 2 (52). C. 134-139.

3. Мельчук И. А. Опыт теории лингвистических моделей «СМЫСЛ <-> ТЕКСТ». М.: Школа «Языки русской культуры», 1999. 346 с.

4. Борисова Е. Г. Коллокации. Что это такое и как их изучать. М.: Филология, 1995. 49 с.

5. Тиханович А. Н. Лексическая функция magn в современном русском языке: корпусное и экспериментальное изучение: дис. ... канд. филол. наук: 10.02.01. СПб, 2009. 194 с. 